\title{
Continuation of Methotrexate Resulted in Better Clinical and Radiographic Outcomes Than Discontinuation upon Starting Etanercept in Patients with Rheumatoid Arthritis: 52-week Results from the JESMR Study
}

\author{
HIDETO KAMEDA, KATSUAKI KANBE, ERI SATO, YUKITAKA UEKI, KAZUYOSHI SAITO, SHOUHEI NAGAOKA, \\ TOSHIHIKO HIDAKA, TATSUYA ATSUMI, MICHISHI TSUKANO, TSUYOSHI KASAMA, SHUNICHI SHIOZAWA, \\ YOSHIYA TANAKA, HISASHI YAMANAKA, and TSUTOMU TAKEUCHI
}

\begin{abstract}
Objective. The aim of the Efficacy and Safety of Etanercept on Active Rheumatoid Arthritis Despite Methotrexate Therapy in Japan (JESMR) study is to compare the efficacy of continuation versus discontinuation of methotrexate (MTX) when starting etanercept (ETN) in patients with active rheumatoid arthritis (RA).

Methods. In total, 151 patients with active RA who had been taking MTX were randomized to either ETN $25 \mathrm{mg}$ twice a week with 6-8 mg/week MTX (the E+M group), or ETN alone (the E group). The primary endpoint at Week 52 was the radiographic progression assessed by van der Heijde-modified Sharp score.

Results. The mean progression in total score at Week 52 was not significantly different, statistically, between the $\mathrm{E}+\mathrm{M}$ group and the $\mathrm{E}$ group $(0.8$ vs 3.6 , respectively; $\mathrm{p}=0.06)$. However, a significant difference was observed in radiographic progression between Weeks 24 and 52 ( 0.3 vs $2.5 ; p=0.03)$, and the mean progression of the erosion score was negative in the E+M group, which was significantly better than the E group at Week $52(-0.2$ vs $1.8 ; \mathrm{p}=0.02)$. Clinically, the cumulative probability plot of the American College of Rheumatology (ACR)-N values at Week 52 clearly demonstrated a superior response in the E+M group than in the E group. ACR20, 50, and 70 response rates at Week 52 in the E+M group $(86.3 \%, 76.7 \%$, and $50.7 \%)$ were significantly greater than those in the E group $(63.8 \%$; $\mathrm{p}=0.003,43.5 \% ; \mathrm{p}<0.0001$ and $29.0 \% ; \mathrm{p}=0.01$, respectively $)$.

Conclusion. MTX should be continued when starting ETN in patients with active RA. (ClinicalTrials.gov: NCT00688103) (First Release May 15 2011; J Rheumatol 2011;38:1585-92; doi:10.3899/jrheum.110014)
\end{abstract}

From the Japan Biological Agent Integrated Consortium (JBASIC); Division of Rheumatology, Keio University; Department of Orthopedics, Medical Center East, and Institute of Rheumatology, Tokyo Women's Medical University; Division of Rheumatology and Clinical Immunology, Showa University School of Medicine, Tokyo; Rheumatic and Collagen Disease Center, Sasebo Chuo Hospital, Sasebo; First Department of Internal Medicine, University of Occupational and Environmental Health, Kitakyushu; Department of Rheumatology, Yokohama Minami Kyosai Hospital, Yokohama; Institute of Rheumatology, Zenjinkai Shimin-No-Mori Hospital, Miyazaki; Department of Medicine II, Hokkaido University Graduate School of Medicine, Sapporo; Kumamoto Orthopaedic Hospital, Kumamoto; and The Center for Rheumatic Diseases, Kobe University Hospital, Kobe, Japan.

Supported by the Advanced Clinical Research Organization (Japan) and by research grants from the Japanese Ministry of Health, Labor and Welfare.

H. Kameda, MD, PhD, Assistant Professor; T. Takeuchi, MD, PhD, Professor, Division of Rheumatology, Keio University; K. Kanbe, MD, PhD, Associate Professor, Department of Orthopedics, Medical Center East, Tokyo Women's Medical University; E. Sato, MD; H. Yamanaka, MD, PhD, Professor, Institute of Rheumatology, Tokyo Women's Medical
University; Y. Ueki, MD, PhD, Rheumatic and Collagen Disease Center, Sasebo Chuo Hospital; K. Saito, MD, PhD, Associate Professor; Y. Tanaka, MD, PhD, Professor, First Department of Internal Medicine, University of Occupational and Environmental Health; S. Nagaoka, MD PhD, Department of Rheumatology, Yokohama Minami Kyosai Hospital; T. Hidaka, MD, PhD, Institute of Rheumatology, Zenjinkai Shimin-No-Mori Hospital; T. Atsumi, MD, PhD, Associate Professor, Department of Medicine II, Hokkaido University Graduate School of Medicine; M. Tsukano, MD, PhD, Kumamoto Orthopaedic Hospital;

T. Kasama, MD, PhD, Associate Professor, Division of Rheumatology and Clinical Immunology, Showa University School of Medicine;

S. Shiozawa, MD, PhD, Professor, The Center for Rheumatic Diseases, Kobe University Hospital.

Address correspondence to Dr. H. Kameda, Division of Rheumatology, Department of Internal Medicine, School of Medicine, Keio University, 35 Shinanomachi, Shinjuku-ku, Tokyo 160-8582, Japan.

E-mail: kamehide@z6.keio.jp

Full Release Article. For details see Reprints/Permissions at jrheum.org Accepted for publication March 15, 2011. 
The introduction of biological agents such as tumor necrosis factor- $\alpha$ (TNF- $\alpha$ ) inhibitors into the therapeutic strategy for rheumatoid arthritis (RA) resulted in a shift characterized by the sufficient inhibition of arthritic signs and symptoms, radiographic progression, and functional disability ${ }^{1,2}$. However, the optimal use of those agents remains to be determined. For example, etanercept (ETN) has been shown to be effective for RA both as a monotherapy and as combination therapy with methotrexate (MTX), and the latter has proved its superiority to the former in MTX-naive patients. Because MTX is the first-line drug for most patients with RA, and ETN is much more expensive than MTX, ETN tends to be started for MTX-refractory, but not MTX-naive, patients in actual clinical practice ${ }^{3,4}$.

The Add Enbrel or Replace Methotrexate (ADORE) trial was the first to consider whether adding ETN to MTX is better than replacing MTX with ETN. The trial failed to demonstrate the superiority of continuing MTX rather than discontinuing it upon starting ETN therapy ${ }^{5}$. Because the ADORE trial was only 16 weeks, with a regimen of MTX tapering over the initial 4 weeks, there could be no marked difference between continuation versus discontinuation of MTX, if any difference at all. Longterm efficacy and safety was not compared between the 2 groups.

Therefore, we conducted the Efficacy and Safety of Etanercept on Active Rheumatoid Arthritis Despite Methotrexate Therapy in Japan (JESMR) study to address the differences in clinical activity, radiographic progression, and functional disability over 2 years. The 24-week results from the JESMR study demonstrated that continuation of MTX after the start of ETN was better than discontinuation of MTX, in terms of European League Against Rheumatism (EULAR) response and American College of Rheumatology (ACR20) response rates $^{6}$. We report the 52 -week results, focusing on the radiographic progression measured by van der Heijde-modified Sharp (vdH-Sharp) score (which had been included in the co-primary endpoint), the ACR response ${ }^{7}$, and functional disability evaluated by the Health Assessment Questionnaire-Disability Index (HAQ-DI) ${ }^{8}$.

\section{MATERIALS AND METHODS}

Patients. Our prospective, randomized, open-label study was conducted at 45 institutions in Japan between June 2005 and January 2007. The study protocol (ClinicalTrials.gov: NCT00688103) was approved by an institutional ethics committee of each participating institute. All patients provided written informed consent in accord with the Declaration of Helsinki.

Patients had to be at least 18 years of age, had to fulfill the ACR 1987 revised classification criteria for RA, and had to meet the guidelines for the proper use of ETN in Japan [having at least 6 tender joints and 6 swollen joints, and either a serum C-reactive protein level of $>2 \mathrm{mg} / \mathrm{dl}$ or erythrocyte sedimentation rate $(E S R) \geq 28 \mathrm{~mm}$ at $1 \mathrm{~h}$, with adequate safety profiles] $]^{9}$. Precise inclusion and exclusion criteria have been reported ${ }^{6}$.

Baseline characteristics of the patients were comparable between the ETN group (E group) and the ETN + MTX group (E+M group) ${ }^{6}$. More than $80 \%$ of the patients were women, at an average age of around 57 years, and with a disease duration of around 9 years (Table 1).

The rheumatoid factor was positive in about $90 \%$ of patients. The mean
MTX dose at enrollment was $7 \mathrm{mg} /$ week, with supplementary folic acid in $38 \%-52 \%$ of patients ${ }^{6}$. The baseline total vdH-Sharp score and its estimated yearly progression at study entry were very high in both groups, indicating the severity of disease of our patients (Table 1).

Procedures. Patients who had agreed to receive ETN for active RA were randomly assigned to continue MTX (6-8 mg/wk, an approved dose in Japan during the study period), that is, MTX + ETN combination therapy, or to discontinue MTX and switch to ETN monotherapy. Enrollment and randomization were performed on the University Hospital Medical Information Network Website (Tokyo, Japan) on the day of obtaining informed consent. Between June 2005 and January 2007, a total of 151 patients from 34 institutes in Japan were enrolled in the JESMR study. All patients enrolled were treated with ETN $25 \mathrm{mg}$ as a subcutaneous injection twice weekly.

The co-primary endpoints of the JESMR study showed a good response according to the EULAR criteria, as based on a 28-joint Disease Activity Score (DAS28) and the ACR50 response rate at Week 24, as reported ${ }^{6}$, and the radiographic progression assessed by vdH-Sharp score ranged from 0 to 448 over 52 weeks $^{10}$. Two trained readers independently scored each radiograph of hands and feet at baseline and at Weeks 24 and 52. Patient identities and treatment groups were blinded to the readers, although the chronological sequence of the radiographs in sets was unmasked. The smallest detectable difference between readers at baseline was 9.9 (standard deviation of the perpatient difference between the readers divided by the square root of 2), and the smallest detectable change over 52 weeks was 1.9.

Statistical analysis. A sample size of 150 patients per treatment group was first calculated to provide $>90 \%$ power $(\alpha=0.05, \beta=0.1)$ with $15 \%$ noncompletion rate during 24 weeks. This calculation assumed that the ACR50 response rate would be $40 \%$ in the $\mathrm{E}$ group and $60 \%$ in the $\mathrm{E}+\mathrm{M}$ group. However, because of the delay in patient recruitment, we completed the patient enrollment in January 2005 at a total of 151 patients (74 in the E group and 77 in the $\mathrm{E}+\mathrm{M}$ group). This decision was based on the calculation that a sample size of 64 per treatment group was needed to provide more than $90 \%$ power $(\alpha=0.05, \beta=0.1)$, assuming that the mean radiographic progression by vdH-Sharp score at 52 weeks would be 1.50 in the E group and -0.80 in the $\mathrm{E}+\mathrm{M}$ group.

Efficacy analyses included all patients who took the study drugs and had a valid baseline and $\geq 1$ on-therapy value for each endpoint. The last observation carried forward (LOCF) and linear imputation were used for the analysis of clinical and radiographic efficacy, respectively, for missing data. All analyses were performed by the CMIC Co. Ltd. Data Center (Osaka, Japan). The proportions of participants who met given criteria were compared with Fisher's exact test, while the mean values between the groups were compared with the Mann-Whitney U test.

\section{RESULTS}

Primary endpoint: radiographic efficacy. Efficacy analysis was performed in 69 patients of the E group and 73 of the $\mathrm{E}+\mathrm{M}$ group (Figure 1). The rate of per-protocol patients was smaller in the $\mathrm{E}$ group than in the $\mathrm{E}+\mathrm{M}$ group, chiefly because of a lack of efficacy after 24 weeks.

The baseline vdH-Sharp score was $114.5 \pm 85.7$ in the $\mathrm{E}$ group and $113.1 \pm 85.6$ in the $\mathrm{E}+\mathrm{M}$ group $(\mathrm{p}=0.99)$. Cumulative probability plot analysis suggested less overall radiographic progression in the $\mathrm{E}+\mathrm{M}$ group than in the $\mathrm{E}$ group during the 52 weeks (Figure 2A). However, the primary endpoint at 52 weeks was not met because the numerical superiority of the $\mathrm{E}+\mathrm{M}$ group over the $\mathrm{E}$ group in the change in vdH-Sharp score over 52 weeks did not reach a statistically significant difference ( 0.8 vs 3.6 , respectively; $\mathrm{p}=0.06)$, as shown in Figure 2B. Nonetheless, the mean progression in the erosion score was negative exclusively in the E+M group, at 
Table 1. Demographic features of the patients. Except where indicated otherwise, values are mean \pm SD

\begin{tabular}{lccc}
\hline Characteristics & ETN, $\mathrm{n}=71$ & ETN + MTX, $\mathrm{n}=76$ & $\mathrm{p}$ \\
\hline Age, yrs & $58.1 \pm 12.6$ & $56.6 \pm 11.1$ & 0.23 \\
Women, $\%$ & 87.3 & 80.3 & 0.27 \\
Body weight, $\mathrm{kg}$ & $51.0 \pm 8.4$ & $54.6 \pm 11.3$ & 0.057 \\
Disease duration, yrs & $10.6 \pm 10.5$ & $8.0 \pm 7.6$ & 0.21 \\
Positive rheumatoid factor, $\%$ & 91.5 & 76.7 & 0.43 \\
MTX dose, mg/wk & $7.0 \pm 1.4$ & $113.1 \pm 85.6(89.5 ; 91.0)$ & 0.099 \\
Total vdH-Sharp score, (median; IQR) & $114.5 \pm 85.7(94.5 ; 120.0)$ & $20.8 \pm 18.2(4.4 ; 12.2)$ & 0.99 \\
Estimated yearly progression, (median; IQR) & $17.7 \pm 13.2(13.9 ; 16.0)$ & $56.6 \pm 54.4(37.8 ; 53.0)$ & 0.45 \\
Erosion score, (median; IQR) & $55.6 \pm 53.0(43.5 ; 59.5)$ & $56.5 \pm 32.9(47.8 ; 41.4)$ & 0.79 \\
Joint space narrowing score, (median; IQR) & $58.9 \pm 33.9(54.0 ; 55.0)$ & \\
\hline
\end{tabular}

ETN: etanercept; MTX: methotrexate; vdH: van der Heijde; IQR: interquartile range.

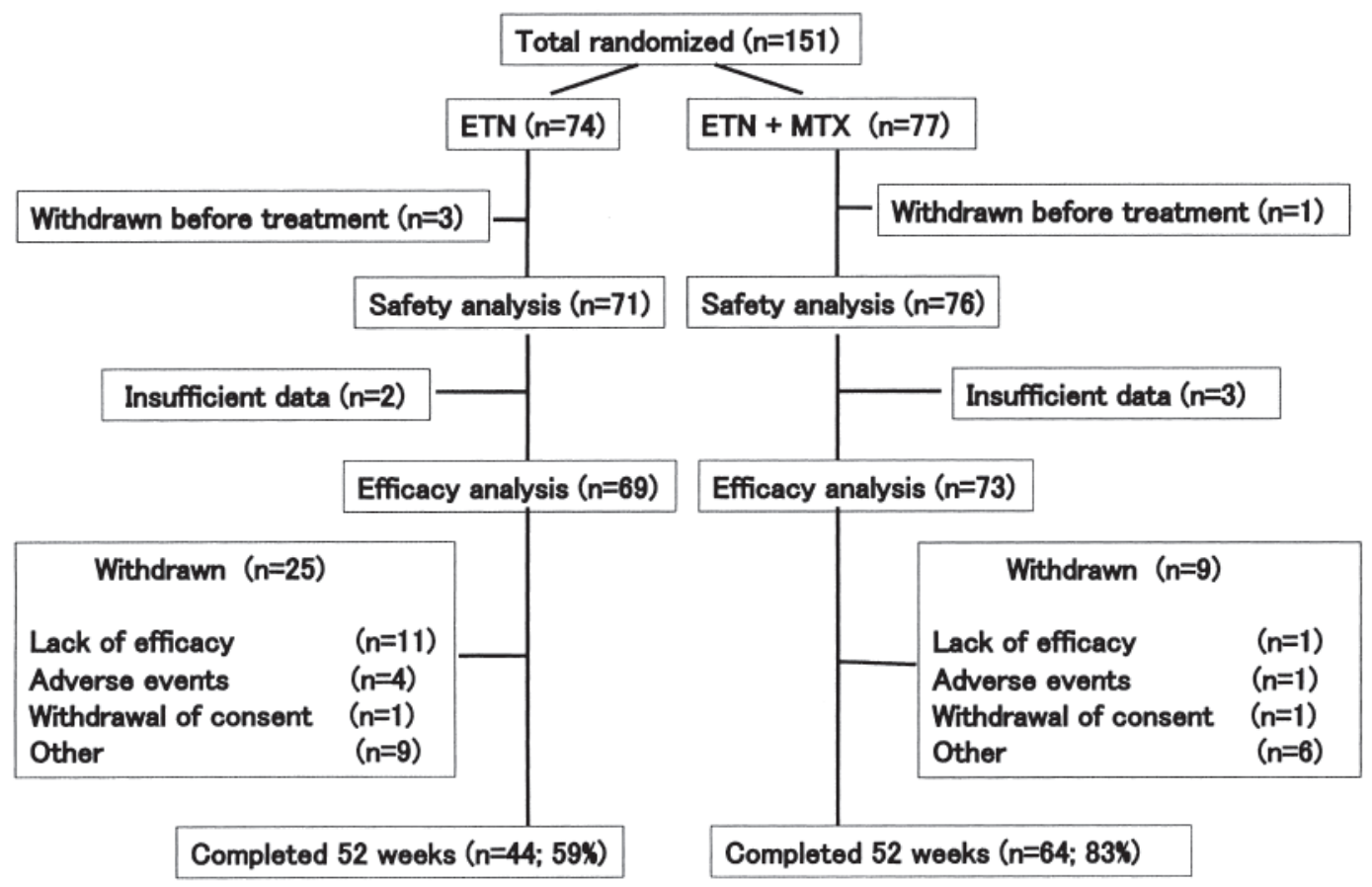

Figure 1. Disposition of patients during 52 weeks of the Efficacy and Safety of Etanercept on Active Rheumatoid Arthritis Despite Methotrexate Therapy in Japan (JESMR) study. A total of 151 patients were enrolled, 74 in the etanercept (ETN) group and 77 in the etanercept and methotrexate (MTX) group, and 108 patients (71.5\%) completed 52 weeks per protocol.

both 24 weeks and 52 weeks ( -0.1 and -0.2 , respectively), and it was significantly better than that in the E group at 52 weeks $(1.8 ; \mathrm{p}=0.02)$. Moreover, a significant difference was observed in the total score progression between Weeks 24 and 52 (2.5 in the E group and 0.3 in the $\mathrm{E}+\mathrm{M}$ group; $\mathrm{p}=0.03$ ), suggesting the carrying-over effect of MTX for the initial few months.

The proportion of patients showing no radiographic progression over 52 weeks (change in vdH-Sharp score $\leq 0.5$ ) was $39.6 \%$ in the E group and $57.4 \%$ in the $\mathrm{E}+\mathrm{M}$ group ( $\mathrm{p}=$ 0.07 ), and the proportion showing no clinically significant radiographic progression (change in vdH-Sharp score $\leq$ smallest detectable change) was $58.5 \%$ in the E group and $67.6 \%$ in the $\mathrm{E}+\mathrm{M}$ group $(\mathrm{p}=0.34)$.
Clinical efficacy. Next we performed for the first time a cumulative probability plot analysis of ACR-N values at 52 weeks for both treatment groups (Figure 3). This analysis clearly demonstrated the superior clinical response in the $\mathrm{E}+\mathrm{M}$ group compared to the $\mathrm{E}$ group, and implied that the continuation of MTX would be beneficial, at least to some extent, in nearly $80 \%$ of patients upon the commencement of ETN. Indeed, the mean \pm SD of ACR-N was $60.9 \pm 29.3$ for the E+M group, which was significantly greater than that of the E group (31.1 $\pm 50.8 ; \mathrm{p}=0.0003$ ). In addition, the area under the curve of the ACR-N throughout 52 weeks was also significantly different between the groups $(26.8 \pm 13.0$ in the $\mathrm{E}+\mathrm{M}$ group and $18.4 \pm 19.0$ in the E group; $p=0.008$ ). At the same time, we could easily see the superior ACR response rates in the E+M Personal non-commercial use only. The Journal of Rheumatology Copyright $@$ $~ 2011$. All rights reserved. 


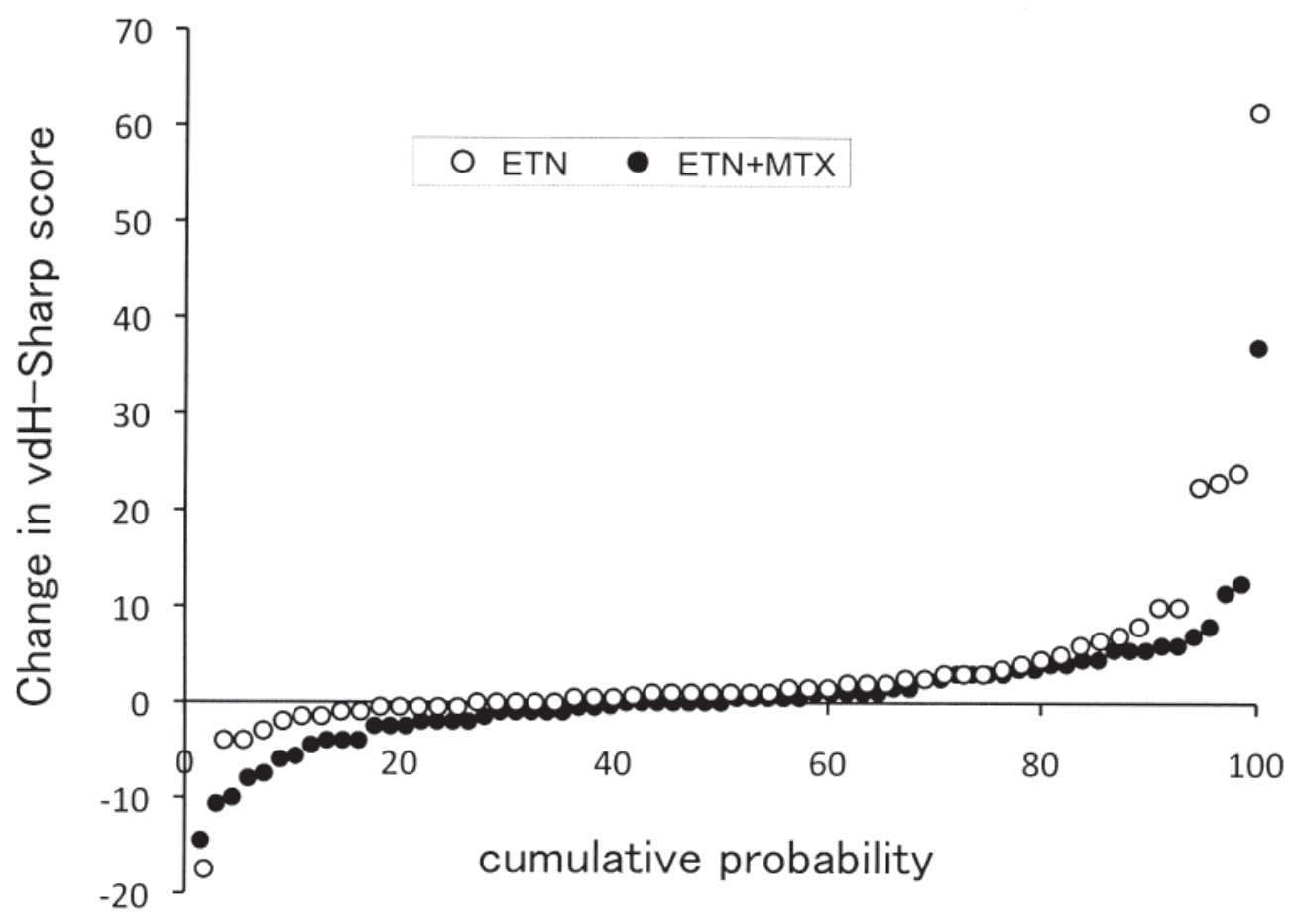

B

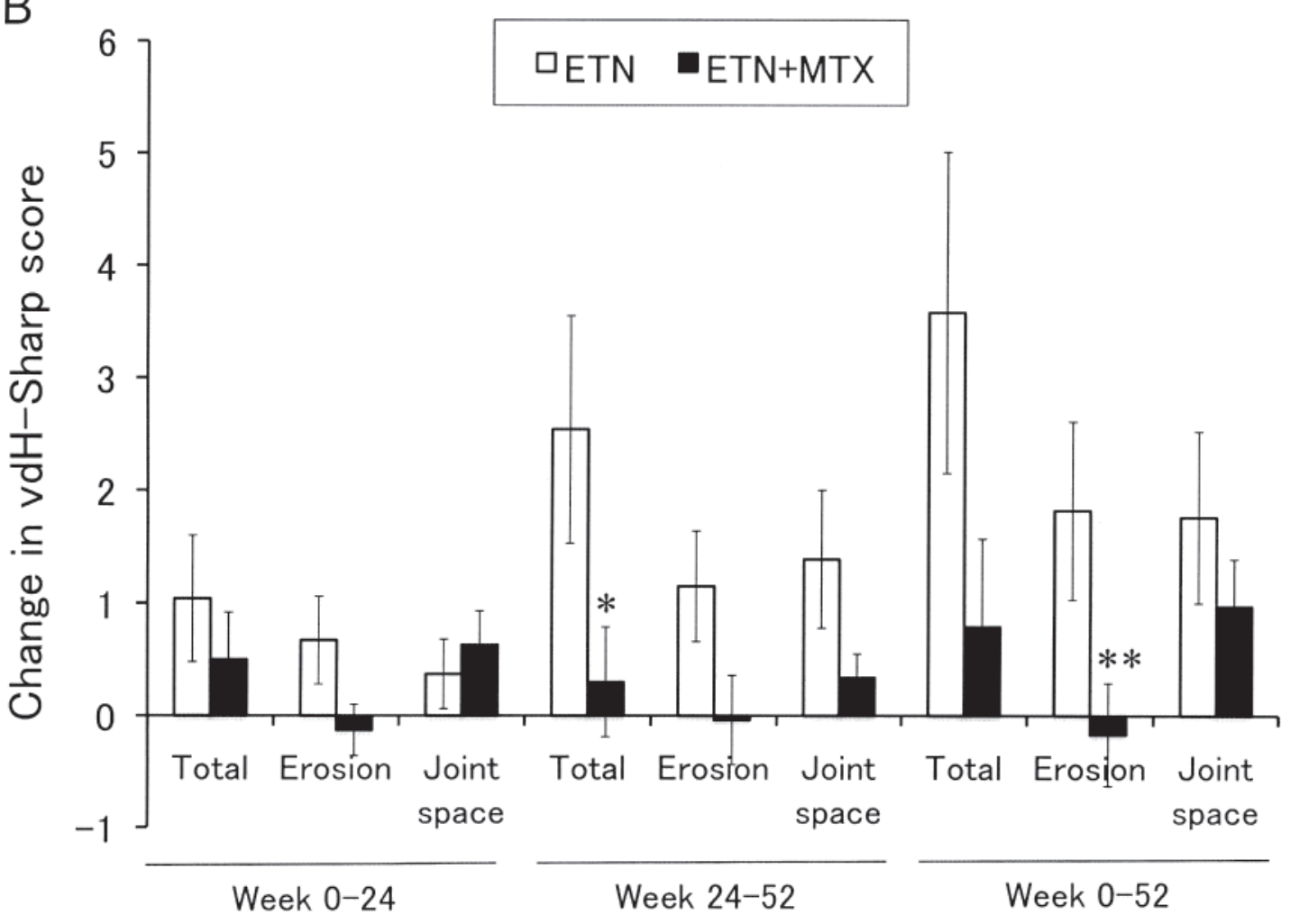

Figure 2. Change in van der Heijde-modified Sharp (vdH-Sharp) total score represented by cumulative probability plot (A) and the mean change of total score as well as erosion and joint space narrowing scores (B) over 52 weeks. Values are mean \pm SEM, compared by Mann-Whitney U test $(* \mathrm{p}=0.03 ; * * \mathrm{p}=0.02)$ between groups. ETN: etanercept group; ETN+MTX: etanercept plus methotrexate group. 


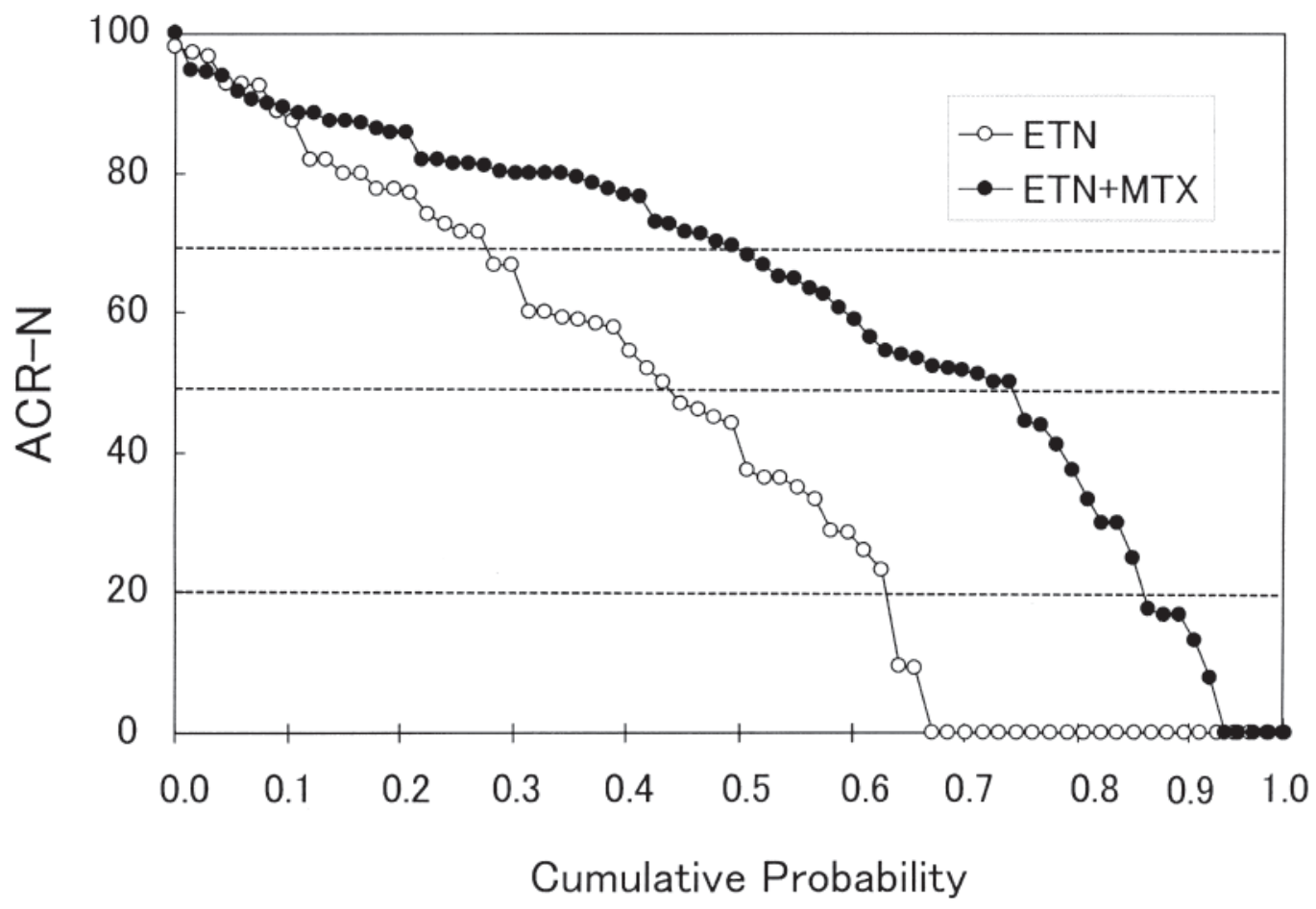

Figure 3. American College of Rheumatology (ACR) values at 52 weeks; 69 patients in the etanercept group (ETN) and 73 in the etanercept plus methotrexate group (ETN+MTX) were analyzed. Broken lines indicate ACR20, ACR50, and ACR70 values.

group compared to the E group, as shown in Figure 3: 86.3\% vs $63.8 \%$ in ACR20 ( $\mathrm{p}=0.003), 76.7 \%$ vs $43.5 \%$ in ACR50 ( $\mathrm{p}<0.0001$ ), and $50.7 \%$ vs $29.0 \%$ in ACR70 ( $\mathrm{p}=0.01$ ), respectively (Table 2). Except for patient global assessment, all important clinical measures, including HAQ-DI, favored the continuation of MTX at Week 52, as shown in Table 2.

Safety analyses. Safety profiles between the 2 treatment groups were comparable (Table 3). Similar overall adverse events were observed between the treatment groups. The frequency of general disorders and administration site conditions, mostly injection site reaction (13 in the E group and 7 in the $\mathrm{E}+\mathrm{M}$ group), tended to be higher in the $\mathrm{E}$ group than the $\mathrm{E}+\mathrm{M}$ group, as well as skin and subcutaneous tissue disorders including eczema and erythema developed at sites unrelated

Table 2. Comparison of the clinical responses between treatment groups. Except where indicated otherwise, values are mean \pm SD.

\begin{tabular}{|c|c|c|c|c|c|c|c|}
\hline \multirow[t]{2}{*}{ Measures } & \multicolumn{3}{|c|}{ ETN, $n=69$} & \multicolumn{3}{|c|}{$\mathrm{MTX}+\mathrm{ETN}, \mathrm{n}=73$} & \multirow{2}{*}{$\begin{array}{c}\mathrm{p} \text { at } 52 \text { Weeks } \\
\text { Between Groups }\end{array}$} \\
\hline & 0 Week & 52 Weeks & $\mathrm{p}$ & 0 Week & 52 Weeks & $\mathrm{p}$ & \\
\hline Tender joint count (68 assessed) & $15.0 \pm 9.4$ & $4.3 \pm 5.3$ & $<0.0001$ & $15.1 \pm 8.1$ & $2.1 \pm 2.8$ & $<0.0001$ & 0.020 \\
\hline Patient global assessment & $62.5 \pm 20.5$ & $27.4 \pm 25.1$ & $<0.0001$ & $53.7 \pm 23.7 *$ & $21.3 \pm 19.4$ & $<0.0001$ & 0.264 \\
\hline $\mathrm{ESR}, \mathrm{mm} / \mathrm{l} \mathrm{h}$ & $59.7 \pm 28.4$ & $43.7 \pm 27.0$ & $<0.0001$ & $59.5 \pm 26.5$ & $28.9 \pm 23.8$ & 0.0002 & 0.0002 \\
\hline $\mathrm{CRP}, \mathrm{mg} / \mathrm{dl}$ & $2.5 \pm 2.5$ & $1.3 \pm 1.6$ & $<0.0001$ & $3.0 \pm 3.2$ & $0.5 \pm 0.8$ & $<0.0001$ & 0.0003 \\
\hline DAS $28<2.6, \%$ & 0 & 18.8 & - & 0 & 35.6 & - & 0.038 \\
\hline ACR20 responder, $\%$ & - & 63.8 & - & - & 86.3 & - & 0.0003 \\
\hline ACR50 responder, \% & - & 43.5 & - & - & 76.7 & - & $<0.0001$ \\
\hline ACR70 responder, $\%$ & - & 29 & - & - & 50.7 & - & 0.001 \\
\hline HAQ-DI & $1.3 \pm 0.8$ & $0.9 \pm 0.7$ & $<0.0001$ & $1.2 \pm 0.7$ & $0.6 \pm 0.6$ & $<0.0001$ & 0.041 \\
\hline
\end{tabular}

* A significant difference between groups was observed at Week 0 (about 4 weeks after enrollment shown in Table 1) for patient's global assessment value, in which p value was 0.025. ETN: etanercept; MTX: methotrexate; ESR: erythrocyte sedimentation rate; CRP: C-reactive protein; DAS28: 28-joint Disease Activity Score; EULAR: European League Against Rheumatism; ACR: American College of Rheumatology; HAQ-DI: Health Assessment Questionnaire-Disability Index.

$$
\text { Personal non-commercial use only. The Journal of Rheumatology Copyright @ 2011. All rights reserved. }
$$


Table 3. Adverse events. Values are numbers of patients who developed (serious) adverse events.

\begin{tabular}{lccc}
\hline Type of Adverse Event & $\begin{array}{c}\text { ETN, } \\
n=71\end{array}$ & $\begin{array}{c}\text { ETN + MTX, } \\
n=76\end{array}$ & $\mathrm{p}$ \\
\hline Blood and lymphatic system disorders & 2 & 0 & 0.232 \\
Cardiac disorders & 0 & $1(1)$ & 1.000 \\
Eye disorders & 1 & 2 & 1.000 \\
Gastrointestinal disorders & 7 & 5 & 0.554 \\
General disorders and administration site conditions & 15 & 7 & 0.063 \\
Hepatobiliary disorders & 1 & 5 & 0.211 \\
Infections and infestations & 19 & $21(2)$ & 1.000 \\
Injury, poisoning, procedural complications & $3(2)$ & $5(3)$ & 0.720 \\
Metabolism and nutrition disorders & 1 & 2 & 1.000 \\
Musculoskeletal and connective tissue disorders & 2 & 0 & 0.232 \\
Neoplasms benign, malignant, unspecified & 0 & $1(1)$ & 1.000 \\
Nervous system disorders & 2 & $4(1)$ & 0.682 \\
Psychiatric disorders & 3 & 3 & 1.000 \\
Renal and urinary disorders & 0 & 1 & 1.000 \\
Reproductive system and breast disorders & 0 & 1 & 1.000 \\
Respiratory, thoracic, mediastinal disorders & 3 & 2 & 0.673 \\
Skin and subcutaneous tissue disorders & 11 & 5 & 0.112 \\
Vascular disorders & 1 & 0 & 0.483 \\
Serious adverse events & 2 & 7 & 0.168 \\
\hline
\end{tabular}

ETN: etanercept; MTX: methotrexate.

to ETN injection. In contrast, the frequency of hepatobiliary disorders, mostly liver dysfunction, tended to be higher in the $\mathrm{E}+\mathrm{M}$ group than in the $\mathrm{E}$ group. The result was the same between the groups with metabolism and nutrition disorders such as hyperlipidemia, diabetes mellitus, and hyperuricemia. Serious adverse events in the E group were bone fractures in 2 patients (humeral bone and osteoporotic vertebrae). Serious adverse events in the $\mathrm{E}+\mathrm{M}$ group were bone fractures in 3 (femoral bone in 2, cranial bone in 1), and in 1 patient each, congestive heart failure, cellulitis, herpes zoster, brain hemorrhage, and mammary carcinoma. Cranial bone fracture from a traffic accident and cellulitis developed in the same patient. Treatment was withdrawn because of injection site reaction in 4 patients in the E group and mammary carcinoma in 1 patient in the $\mathrm{E}+\mathrm{M}$ group. Thus, the safety profile was comparable between 2 groups.

\section{DISCUSSION}

In a previous report on the 24-week results of the JESMR study, the superiority of a continuation of MTX over its discontinuation when starting ETN in terms of controlling clinical disease activity (the rates of EULAR good response, remission, and ACR20 response, but not ACR50 and 70 responses) was indicated ${ }^{6}$. Our 52 -week results not only confirmed the previous ones but also proved, for the first time, that the combination of ETN and MTX resulted in a better outcome in radiographic progression determined by $\mathrm{vdH}$-Sharp score, especially in erosions, even in patients who had shown an incomplete response to MTX. The mean progression in total score at Week 52 was not significantly different, statistically, between the E+M group and the E group ( 0.8 vs 3.6 , respectively; $\mathrm{p}=0.06$ ). The chief reason for failure to achieve the primary endpoint seemed to be the reduction in sample size due to delayed recruitment of patients. However, a significant difference was observed in radiographic progression between Weeks 24 and 52 ( 0.3 vs 2.5 , respectively; $\mathrm{p}=$ 0.03 ), and the mean progression of the erosion score was negative in the $\mathrm{E}+\mathrm{M}$ group, which was significantly better than the E group at Week $52(-0.2$ vs 1.8 , respectively; $\mathrm{p}=0.02)$. Further, all important clinical measures, including ACR responses, EULAR responses, and HAQ-DI, favored the continuation of MTX at Week 52.

Infliximab was the first biological agent to have demonstrated complete inhibition of radiographic progression in combination with MTX in MTX-refractory patients with active $\mathrm{RA}^{11}$. ETN and adalimumab showed similar efficacy in halting joint destruction in combination with MTX. Both agents proved their superior clinical and radiographic efficacy with MTX combination over monotherapy in MTX-naive patients with early RA (the PREMIER study ${ }^{12}$ ) or established RA (the TEMPO study ${ }^{13}$ ). Our results led to the conclusion that anti-TNF biological agents should be used in combination with MTX as far as possible, whether the patients are MTX-naive or MTX-refractory, and they strongly support the recent recommendations of the $\mathrm{ACR}^{3}$ and EULAR ${ }^{4}$.

The reason that the continuation of MTX, which had only shown an inadequate response in the enrolled patients, demonstrated a significant effect with ETN treatment may be as follows: (1) the efficacy of MTX was insufficient but not negligible even as a monotherapy; and (2) the targets of MTX, including activated $\mathrm{T}$ cells ${ }^{14}$, are not identical to those of ETN, resulting in additive or synergistic effects between MTX and ETN. A recent report from the GO-FORWARD study also Personal non-commercial use only. The Journal of Rheumatology Copyright @ 2011 . All rights reserved. 
demonstrated a better clinical response to golimumab with MTX continuation than with its discontinuation in MTX-refractory patients with RA ${ }^{15}$. The fact that many clinical (ACR50 and 70 response rates and HAQ-DI score) and radiographic (erosion score progression) measures showed statistically significant differences at Week 52 but not at Week $24^{6}$ may explain why the ADORE study did not show a difference between MTX continuation and discontinuation ${ }^{5,16}$. The usefulness of MTX continuation seems to be true with all biological agents targeting TNF.

The average disease duration of about 9 years significantly affected the radiographic and HAQ-DI results in the JESMR study. Despite a long disease duration, our patients showed a rapid progression in $\mathrm{vdH}$-Sharp scores with a mean estimated yearly progression of 18-21 (Table 1). This result was close to that of patients with early active RA who were enrolled in the PREMIER study $(26-27)^{12}$ and was much higher than that in the TEMPO study $(8-11)^{13}$. This fact may explain, at least in part, the similarities and differences in the radiographic progression results among those clinical trials. In addition, the radiographic progression in our patients could be more aggressive in the initial few years after disease onset. Therefore, whether our results are also true for patients with early RA of $<6$ months' duration should be examined in the near future.

Most of the adverse events, including infections and skin disorders other than injection site reactions, were observed throughout 52 weeks. However, as expected, injection site reaction was less frequent after 24 weeks when compared to our previous report ${ }^{6}$. In contrast, most of the bone fractures, which were the predominant serious adverse events in our study, developed after 24 weeks. This could be attributed at least in part to the improved activity of daily life of our patients treated with ETN as demonstrated by the HAQ-DI improvement (Table 2).

Our study has several limitations. First, it was not double-blinded. Therefore, one may assume there was an awareness of the treatment effect evaluations by physicians and by patients. However, the changes in acute-phase reactants (Table 2) and radiographic results (Figures 2A and 2B) make that unlikely. Further, there were considerable withdrawal rates in the E group (Figure 1), mostly because of a lack of efficacy after 24 weeks. Since this had been expected, because this study was not double-blinded, we applied the LOCF methods for clinical efficacy analyses instead of intention-to-treat analyses. In addition, the sample size of the JESMR study limited the power of detection of differences between the 2 treatment groups. Actual ACR50 response rates and the radiographic progression were greater than our expectations in both treatment groups. Finally, the dose of MTX approved by the Japanese Ministry of Health, Labor and Welfare had been only 6-8 $\mathrm{mg} /$ week throughout this study ${ }^{17,18}$ although, concordantly, the use of supplementary folic acid was also limited to about half of the patients receiv- ing MTX. In February 2011, the Ministry approved MTX use up to $16 \mathrm{mg}$ /week for patients with RA. Nonetheless, overall clinical and radiographic outcomes of infliximab added to MTX 7-9 mg/week in Japan 19,20,21,22,23 were comparable to those in the ATTRACT ${ }^{11}$ and ASPIRE studies ${ }^{24}$.

Future studies may also include the prediction of patient outcome after the start of ETN therapy, addressing the question of who can be sufficiently controlled by simply switching from MTX to ETN, and who can be sufficiently controlled by the addition of ETN to MTX but not by switching from MTX to ETN. These subanalyses are now under investigation in the Japan Biological Agent Integrated Consortium (JBASIC) study group.

Our results demonstrated for the first time that the continuation of MTX resulted in a better clinical and radiographic outcome, at least in some aspects, than its discontinuation after the start of ETN in patients with active RA despite MTX therapy. We also showed the usefulness of cumulative probability plot presentation not only for radiographic progression but also for clinical responses such as ACR-N, which may be included in future clinical trials.

\section{ACKNOWLEDGMENT}

We acknowledge the following investigators, their staff and all institutions, affiliated and otherwise: K. Shiozawa (Konan Kakogawa Hospital); S. Kobayashi (Juntendo University School of Medicine, Koshigaya Hospital); N. Tamura (Juntendo University School of Medicine, Juntendo Hospital); T. Sawada (The University of Tokyo Hospital); S. Yamana (Higashihiroshima Memorial Hospital); Y. Honda (Kurume University Hospital); T. Kojima (Nagoya University Hospital); H. Takahashi (Sapporo Medical University Hospital); T. Sugiyama (Shimoshizu National Hospital); A. Taniguchi (Tokyo Women's Medical University, Institute of Rheumatology); T. Nanki (Tokyo Medical and Dental University Hospital, Faculty of Medicine); M. Yamamura (Aichi Medical University Hospital); K. Kurasawa (Dokkyo Medical University Hospital); K. Chiba (Fukushima Daiichi Hospital); K. Kato (Fujita Health University Hospital); K. Ezawa (Kurashiki Kousai Hospital); T. Fujii (Kyoto University Hospital); S. Nakata (Matsuyama Red Cross Hospital); S Tamachi (Mie Chuo Medical Center); Y. Kawabe (National Hospital Organization Ureshino Medical Center); R. Yano (Okayama University Hospital); T. Kuroiwa (The Hospital of Hyogo College of Medicine); A. Kubota (Toho University Omori Medical Center); Hyogo Prefectural General Rehabilitation Center; Rokko Island Hospital; Kurume University Medical Center; Nagasaki University Hospital of Medicine and Dentistry; Nihon University Itabashi Hospital; Niigata University Medical and Dental Hospital; Osaki Citizens' Hospital; Saiseikai Takaoka Hospital; St. Marianna University School of Medicine Hospital; Taihakusakura Hospital; Tohoku Kosei Nenkin Hospital; Tohoku University Hospital; and Tsukuba University Hospital.

\section{REFERENCES}

1. Keystone EC. Strategies to control disease in rheumatoid arthritis with tumor necrosis factor antagonists - an opportunity to improve outcomes. Nat Clin Pract Rheumatol 2006;2:594-601.

2. Smolen JS, Aletaha D, Koeller M, Weisman MH, Emery P. New therapies for treatment of rheumatoid arthritis. Lancet 2007;370:1861-74.

3. Saag KG, Teng GG, Patkar NM, Anuntiyo J, Finney C, Curtis JR, et al. American College of Rheumatology 2008 recommendations for the use of nonbiologic and biologic disease-modifying antirheumatic drugs in rheumatoid arthritis. Arthritis Rheum 
2008;59:762-84.

4. Smolen JS, Landewé R, Breedveld FC, Dougados M, Emery P, Gaujoux-Viala C, et al. EULAR recommendations for the management of rheumatoid arthritis with synthetic and biological disease-modifying antirheumatic drugs. Ann Rheum Dis 2010;69:964-75.

5. van Riel PL, Taggart AJ, Sany J, Gaubitz M, Nab HW, Pedersen R, et al. Efficacy and safety of combination etanercept and methotrexate versus etanercept alone in patients with rheumatoid arthritis with an inadequate response to methotrexate: the ADORE study. Ann Rheum Dis 2006;65:1478-83.

6. Kameda H, Ueki Y, Saito K, Nagaoka S, Hidaka T, Atsumi T, et al. Etanercept (ETN) with methotrexate (MTX) is better than ETN monotherapy in patients with active rheumatoid arthritis despite MTX therapy: a randomized trial. Mod Rheumatol 2010;20:531-8.

7. Bathon JM, Martin RW, Fleischmann RM, Tesser JR, Schiff MH, Keystone EC, et al. A comparison of etanercept and methotrexate in patients with early rheumatoid arthritis. N Engl J Med 2000;343:1586-93.

8. Fries JF, Spitz P, Kraines RG, Holman HR. Measurement of patient outcome in arthritis. Arthritis Rheum 1983;26:1346-53.

9. Miyasaka N, Takeuchi T, Eguchi K. Guidelines for the proper use of etanercept in Japan. Mod Rheumatol 2006;16:63-7.

10. van der Heijde D. How to read radiographs according to the Sharp/van der Heijde method. J Rheumatol 2000;27:261-3.

11. Lipsky PE, van der Heijde DM, St. Clair EW, Furst DE, Breedveld FC, Kalden JR, et al. Infliximab and methotrexate in the treatment of rheumatoid arthritis. N Engl J Med 2000;343:1594-602.

12. Breedveld FC, Weisman MH, Kavanaugh AF, Cohen SB, Pavelka $\mathrm{K}$, van Vollenhoven R, et al. The PREMIER study: A multicenter, randomized, double-blind clinical trial of combination therapy with adalimumab plus methotrexate versus methotrexate alone or adalimumab alone in patients with early, aggressive rheumatoid arthritis who had not had previous methotrexate treatment. Arthritis Rheum 2006;54:26-37.

13. Klareskog L, van der Heijde D, de Jager JP, Gough A, Kalden $\mathrm{J}$, Malaise M, et al. Therapeutic effect of the combination of etanercept and methotrexate compared with each treatment alone in patients with rheumatoid arthritis: double-blind randomized controlled trial. Lancet 2004;363:675-81.

14. Braun J, Rau R. An update on methotrexate. Curr Opin Rheumatol 2009;21:216-23.
15. Keystone EC, Genovese MC, Klareskog L, Hsia EC, Hall ST, Miranda PC, et al. Golimumab, a human antibody to tumour necrosis factor a given by monthly subcutaneous injections, in active rheumatoid arthritis despite methotrexate therapy: the GO-FORWARD Study. Ann Rheum Dis 2009;68:789-96.

16. van Riel PL, Freundlich B, MacPeek D, Pedersen R, Foehl JR, Singh A, et al. Patient-reported health outcomes in a trial of etanercept monotherapy versus combination therapy with etanercept and methotrexate for rheumatoid arthritis: the ADORE trial. Ann Rheum Dis 2008;67:1104-10.

17. Kameda H, Amano K, Sekiguchi N, Takei H, Ogawa H, Nagasawa $\mathrm{H}$, et al. Factors predicting the response to low-dose methotrexate therapy in patients with rheumatoid arthritis: a better response in male patients. Mod Rheumatol 2004;14:442-6.

18. Takeuchi T, Kameda H. The Japanese experience with biologics. Nat Rev Rheumatol 2010;6:644-52.

19. Kameda H, Sekiguchi N, Nagasawa H, Amano K, Takei H, Suzuki $\mathrm{K}$, et al. Development and validation of handy rheumatoid activity score with 38 joints (HRAS38) in rheumatoid arthritis patients receiving infliximab. Mod Rheumatol 2006;16:381-8.

20. Yamanaka H, Tanaka Y, Sekiguchi N, Inoue E, Saito K, Kameda H, et al. Retrospective study on the notable efficacy and related factors of infliximab therapy in a rheumatoid arthritis management group in Japan (RECONFIRM). Mod Rheumatol 2007;17:28-32.

21. Tanaka Y, Takeuchi T, Inoue E, Saito K, Sekiguchi N, Sato E, et al. Retrospective study on the notable efficacy and related factors of infliximab therapy in a rheumatoid arthritis management group in Japan: one-year clinical outcome (RECONFIRM-2). Mod Rheumatol 2008;18:146-52.

22. Takeuchi T, Yamanaka H, Inoue E, Nagasawa H, Nawata M, Ikari $\mathrm{K}$, et al. Retrospective clinical study on the notable efficacy and related factors of infliximab therapy in a rheumatoid arthritis management group in Japan: One-year outcome of joint destruction (RECONFIRM-2J). Mod Rheumatol 2008;18:447-52.

23. Tanaka Y, Takeuchi T, Mimori T, Saito K, Nawata M, Kameda H, et al. Discontinuation of infliximab after attaining low disease activity in patients with rheumatoid arthritis: RRR (remission induction by Remicade in RA) study. Ann Rheum Dis 2010;69:1286-91.

24. St. Clair EW, van der Heijde DM, Smolen JS, Maini RN, Bathon JM, Emery P, et al. Combination of infliximab and methotrexate therapy for early rheumatoid arthritis. A randomized, controlled trial. Arthritis Rheum 2004;50:3432-43. 